\title{
Synchronous mother and calf foraging behaviour in humpback whales Megaptera novaeangliae: insights from multi-sensor suction cup tags
}

\author{
Reny B. Tyson ${ }^{1, *}$, Ari S. Friedlaender ${ }^{1}$, Colin Ware $^{2}$, Alison K. Stimpert ${ }^{3,4}$, \\ Douglas P. Nowacek ${ }^{1,5}$

\begin{abstract}
${ }^{1}$ Duke University Marine Laboratory, Beaufort, North Carolina 28516, USA
${ }^{2}$ Center for Coastal and Ocean Mapping, University of New Hampshire, Durham, New Hampshire 03824, USA

${ }^{3}$ Marine Mammal Research Program, Hawai'i Institute of Marine Biology, Kailua, Hawai'i 96744, USA

${ }^{4}$ Naval Postgraduate School, Department of Oceanography, Monterey, California 93943, USA

${ }^{5}$ Pratt School of Engineering, Duke University, Durham, North Carolina 90271, USA
\end{abstract}

\begin{abstract}
Previously, all inferences regarding fine-scale baleen whale mother-calf relationships have come from surface observations, aerial surveys, or underwater video recordings. On May 19, 2010, we attached high-resolution digital acoustic recording tags (Dtags) to an adult female humpback whale Megaptera novaeangliae and her calf in Wilhelmina Bay (Western Antarctic Peninsula) to examine their concurrent diving and foraging behaviour. The Dtags logged $\sim 20 \mathrm{~h}$ of concurrent recordings. We used cross-correlation analyses to quantify synchrony between the pair. Dive depth was positively correlated for the duration of the concurrent record and was highest when the calf's track lagged behind the mother's by $4.5 \mathrm{~s}$, suggesting that the calf was 'following' its mother. Pitch and heading were positively correlated but to a lesser degree. Both animals executed feeding lunges; however, the mother foraged more intensively than the calf (792 and 118 lunges over 246 and 30 feeding dives, respectively). Also, the mother fed consistently once she initiated feeding at 16:22:00 $\mathrm{h}$ until the tag came off, whereas the calf executed 95.76\% of its lunges between 17:00:08 and 19:28:21 h, local time. Correlation coefficients calculated per dive were highest when both animals were feeding and lowest when only the mother was feeding. In addition, 84.26 and $79.63 \%$ of the calf's lunges were performed within $\pm 20 \mathrm{~s}$ and $\pm 20 \mathrm{~m}$ of its mother's lunges, respectively. Our work describes the first record of a long-term continuous underwater relationship and foraging behaviour of a humpback mother-calf pair.
\end{abstract}

KEY WORDS: Humpback whale $\cdot$ Mother and calf $\cdot$ Foraging $\cdot$ Synchrony $\cdot$ Antarctica

\section{INTRODUCTION}

Synchronised behaviours (animals in proximity to one another, performing the same behaviour at the same time), usually in parallel orientation (Fellner et al. 2006), are common in the early stages of cetacean mother-calf relationships (e.g. Bel'Kovich 1991, Gubbins et al. 1999, Fellner et al. 2006). Synchrony serves several functions, such as receiving an aero- or hydrodynamic advantage by slipstreaming (Weihs 2004, Noren et al. 2008, Noren \& Edwards 2011), pro- tection from predators (Norris \& Schilt 1988), and social learning via imitation during developmental stages that are critical to survival (e.g. independent foraging behaviour; Whiten \& Ham 1992, Whiten 2001, Fellner et al. 2006, Bender et al. 2009, Sargeant \& Mann 2009). Synchronised behaviours observed in mother-calf southern right whale Eubalaena australis and humpback whale Megaptera novaeangliae pairs have provided evidence to suggest that mysticetes (baleen whales) and other cetaceans exhibit 'following' behaviour (Taber \& Thomas 1982, Thomas 
\& Taber 1984, Szabo \& Duffus 2008): a strategy for offspring protection in which the offspring accompany their mother soon after parturition and are rarely more than several body lengths from her until they separate permanently (Lent 1974). 'Following' benefits the mother by not requiring her to return to her offspring, and benefits the offspring by gaining maternal vigilance and defence as a means of predator avoidance and protection (Espmark 1971, Lent 1974, Estes 1976, Fisher et al. 2002). Therefore, synchronised behaviours associated with following in cetacean mother-calf pairs may be critical for the success of the calf's behavioural development.

Humpbacks and other baleen whales are constrained in the 'following' strategy in that their young typically suffer from a reduced physiological capacity to dive relative to older conspecifics and therefore do not dive as frequently or as long as their mothers (Würsig et al. 1984, Szabo \& Duffus 2008). If the mother-calf pair does not want to lose the benefits of their close proximity when the mother makes long-duration dives (e.g. foraging dives), one individual must actively modify its behaviour in relation to the other individual. On a foraging ground in southeastern Alaska, humpback whale mothers modified their behaviour in the beginning of the foraging season by shortening the duration of their dives whenever their offspring remained at the surface, presumably to minimise the duration of their separation (Szabo \& Duffus 2008). Later in the season, however, as the calves grew and gained independence, the mothers became significantly less responsive to their offspring and performed longer dives, thereby forcing their offspring to actively modify their behaviours and increasingly synchronise their dives with their mothers (Szabo \& Duffus 2008). This shift has also been documented in southern right whales where calves are primarily responsible for maintaining contact with their mothers at the end of their foraging season (Taber \& Thomas 1982). Thus, the mother's foraging efficiency (i.e. amount of energy consumed per unit of energy expended while acquiring food) may be low early in the foraging season because she is primarily responsible for maintaining the pair's proximity and may increase later in the season as the calf takes over this responsibility. In addition, once the calf can begin to forage independently, the energetic burden of lactation for the mother will decrease. Humpback calves may begin to feed independently as early as 6 mo old, although they may nurse for up to a year (Van Lennep \& Van Utretcht 1953, Chittleborough 1958, Clapham \& Mayo 1987).
Humpback whales belong to a group of baleen whales known as rorquals (Balaenopteridae), which in Antarctica forage primarily on small euphausiid crustaceans (e.g. Antarctic krill Euphausiia superba) and other small prey by lunge feeding. Lunge feeding involves accelerating with a burst of energetic fluking towards and engulfing a mass of prey-laden water that may equal up to $2 / 3$ of the animal's body mass (Pivorunas 1979, Brodie 1993). The whales then filter the prey from the ingested water through keratinised plates of baleen and swallow the captured prey. Advancements in bio-logging technologies have enabled a better understanding of the kinematics and energetic costs of lunge feeding in fin whales Balaenoptera physalus, blue whales Balaenoptera musculus, and humpback whales (e.g. Goldbogen et al. 2006, 2007, 2008, 2011, Simon 2010, Ware et al. 2011); however, to our knowledge, feeding lunges have not been documented in a mother-calf rorqual pair. Mother-calf pairs have additional energetic and behavioural costs associated with foraging compared to non-lactating females and/or adult males, such as the cost of lactation (mother; Lockyer 2007) and the cost of growth (calf). Understanding the foraging behaviour of mother-calf pairs is critical for understanding their energetic demands during the calf's first year.

In the Southern Ocean, humpback calves are born in the winter and early spring in calving grounds found off Australia, Africa, Oceania, and South America (Chittleborough 1965, Mackintosh 1965, Florez-Gonzalez 1991); early August is the peak birth month (Chittleborough 1958, 1965). Several months later, calves migrate with their mothers to their foraging grounds (e.g. Western Antarctic Peninsula [WAP]; Mackintosh 1965, Clapham 1996) where they typically remain and forage on euphausiids from late spring through late autumn (Baker et al. 1986, Clapham \& Mayo 1987, Baraff \& Weinrich 1993). The majority of mother-calf pairs will separate during, or shortly before, their second winter, although a few pairs remain associated for $2 \mathrm{yr}$ (Clapham \& Mayo 1987, Baraff \& Weinrich 1993).

To our knowledge, all inferences regarding finescale baleen whale mother-calf relationships have come from boat- or land-based surface observations, aerial surveys, or from underwater video recordings (e.g. Taber \& Thomas 1982, Baker et al. 1986, Baraff \& Weinrich 1993, Szabo \& Duffus 2008, Zoidis et al. 2008, Cartwright \& Sullivan 2009). Here, we use data collected from high-resolution digital acoustic recording tags (Dtags; Johnson \& Tyack 2003) to describe the first record of a long-term $(\sim 20 \mathrm{~h})$ continu- 
ous underwater relationship and concurrent foraging behaviour of a baleen whale mother-calf pair. We identify feeding lunges executed by both whales and compare the frequency of lunges and related dive parameters, including the number of lunges per dive, maximum dive depth, dive duration, post-dive surface time, and within-dive inter-lunge interval associated with feeding to assess how these parameters may relate to the energetic demands of each animal. We also examine the synchrony of the pair in terms of their feeding events and their underwater behaviour to assess the structure of the pair's relationship. Based on observations made by Szabo \& Duffus (2008), we predict that the pair's association was waning as the calf was likely 8 to 12 mo old at the time of tagging (i.e. the austral autumn).

\section{MATERIALS AND METHODS}

Dtags (Johnson \& Tyack 2003) are small bio-logging tools developed to continuously collect data on the fine-scale behaviour of marine mammals. On May 19, 2010, we attached Dtags to an adult female humpback whale and her calf in Wilhelmina Bay (WAP; Fig. 1). We approached the pair using a rigidhulled inflatable boat with a 4 -stroke outboard engine and placed the Dtags on the dorsal surface of the whales, between the dorsal fin and the blowhole, using an $8 \mathrm{~m}$ carbon-fibre pole; Dtags attach to the whales via 4 silicone suction cups. The Dtag incorporates a hydrophone (sampling rate up to $96 \mathrm{kHz}$ ), a pressure sensor to measure depth, 3-axis accelerometers, 3axis magnetometers, and an embedded VHF transmitter. The pressure sensors, magnetometers, and accelerometers measure depth, heading, pitch, and roll, respectively, at $50 \mathrm{~Hz}$ and are stored synchronously with audio data on flash memory (16 GB) within the tag. Prior to deployment, the time on the tags was synchronised to the GPS time to ensure the ability to synchronise data parameters (e.g. Friedlaender et al. 2009, Hazen et al. 2009).

The mother was tagged at 11:02:33 $\mathrm{h}$ (tag start time: 11:02:58 h local time, GMT $-5 \mathrm{~h}$ ) while the calf was tagged 49 min later at 11:51:56 h (tag start time: 11:52:17 h) (Fig. 1). Whale behaviour was not visibly affected by the tagging (other than immediate startle responses), which is consistent with reports from other studies (e.g. Nowacek et al. 2004, Hazen et al. 2009). The tagged whales were tracked visually during daylight hours (9:11:00 to 14:59:00 h) from a rigid-hulled inflatable that stayed within $500 \mathrm{~m}$ of the pair and they were tracked with directional VHF antennas at night. An active release, which corrodes in seawater, was timed to release the tags once data storage was complete (approximately $24 \mathrm{~h}$ ), causing the tag to float to the surface. Tags released from the animals at 7:46:00 $\mathrm{h}$ (mother) and 11:52:07 $\mathrm{h}$ (calf) on May 20, 2010. Upon tag retrieval, post-tagging calibration was immediately conducted and the data were downloaded via infrared transmission.

TrackPlot (Ware et al. 2006), a software program designed to interpret data from tags containing accelerometer, magnetometer, and pressure sensors (e.g. Dtags), was used to visualise and analyse the pair's simultaneous 3-dimensional orientations (depth, pitch, roll, and heading). TrackPlot creates a 'pseudotrack' of each whale's movements and behaviours

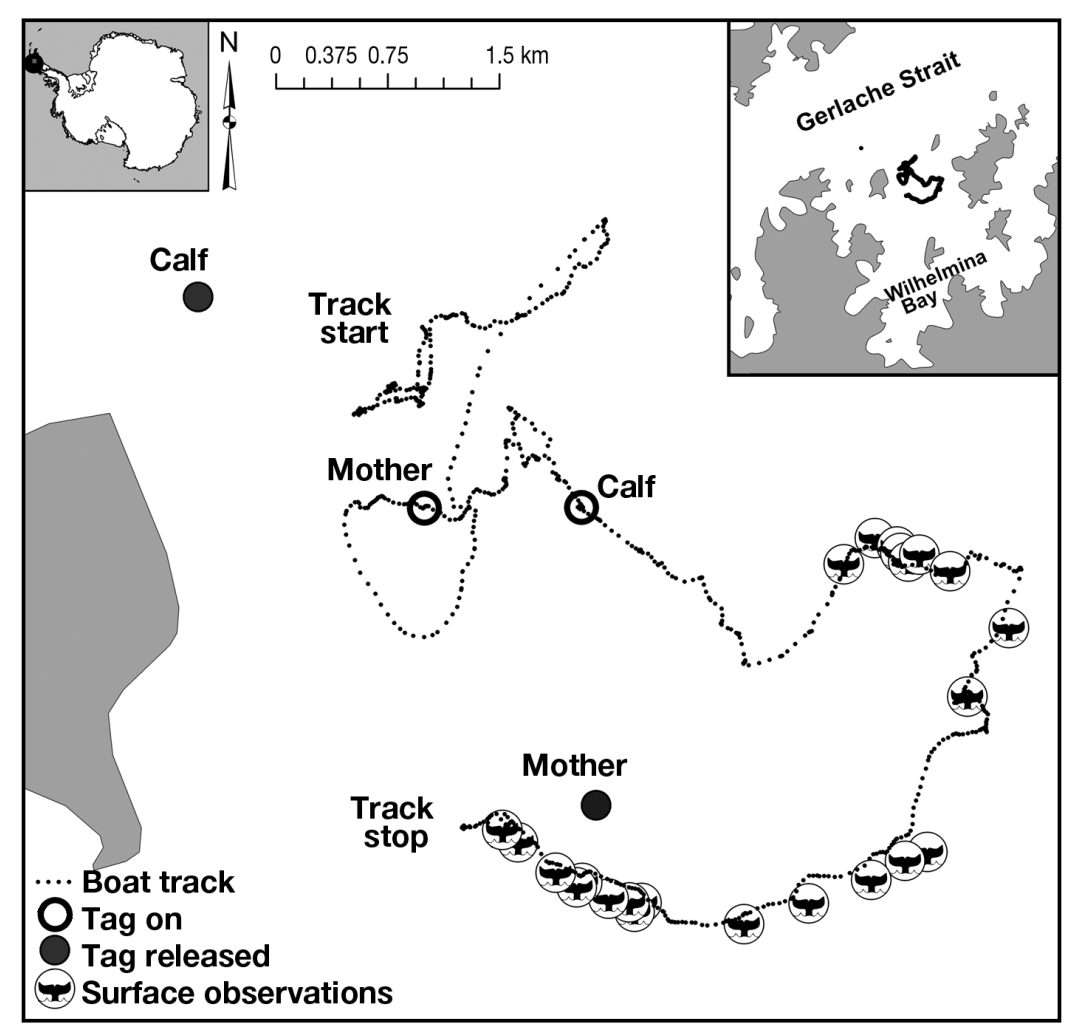

Fig. 1. Megaptera novaeangliae. Locations where the mother and calf were tagged, tracked, and observed at the surface, and where their tags released, from May 19 to 20, 2010, Wilhelmina Bay, Antarctica. Note that the mother's tag released $4 \mathrm{~h} 6$ min before the calf's tag; therefore, the separation in tag off locations is not necessarily representative of the pair being separated in space 
using dead-reckoning based on the time series of whale orientations and by assuming that the whale moves forward in the rostral direction (Ware et al. 2011). The rate of forward movement at any point on the track is either assumed to be constant $\left(1 \mathrm{~m} \mathrm{~s}^{-1}\right)$ or is based on the rate of depth change for an ascending or descending individual divided by the sine pitch of the angle (Ware et al. 2011). Dtags do not provide position information (e.g. GPS points), so known fixes need to be integrated into the dead-reckoning process wherever possible to establish horizontal positions. These known fixes were derived from visual observations made by observers in the rigid-hulled inflatable when the animals surfaced during the Dtag deployment. In this study, most of the tag attachment period was at night and there were only 30 and 27 georeferenced locations made for the mother and calf, respectively, during daylight. Therefore, the lack of fixes for the majority of the concurrent records (e.g. night-time) hinders us from confidently interpreting the pair's absolute geographic position. Instead, we could only assess the pair's vertical proximity to each other in the water column (i.e. calculated as the difference in depth of the pair at each specific time). TrackPlot was also used to extract summary data for each dive (defined here as an excursion $>10 \mathrm{~m}$; Goldbogen et al. 2006), including dive duration (s), post-dive surface time (s), and the maximum depth $(\mathrm{m})$ of each dive. Extracted track and dive data were synchronised in Microsoft $\mathrm{t}^{\circledR}$ Excel based on the time parameter.

Feeding lunges executed by each whale were identified from flow noise recorded on the Dtag hydrophone (Goldbogen et al. 2006, 2008, Simon 2010, Ware et al. 2011). When lunging, a rorqual rapidly accelerates, opens its jaws once a sufficient speed (e.g. $3 \mathrm{~m} \mathrm{~s}^{-1}$ ) has been obtained, and then rapidly decelerates due to the drag forces related to the opening of its buccal cavity (Goldbogen et al. 2006, Potvin et al. 2009); flow noise will simultaneously increase as the animal accelerates and decrease as the animal is slowed. Ware et al. (2011) used flow noise as an estimate of speed to successfully detect lunges from humpback whales and developed an automatic lunge-detecting filter within TrackPlot. The lunge filter (which detects precipitous drops in the animal's speed) allows the user to examine the putative lunges and the animal's estimated speed alongside a pseudo-track of its behaviour aligned in time. We used this filter to detect feeding lunges executed by the mother and the calf. An experienced analyst in TrackPlot then examined the putative lunges and scanned the entire track for missed lunges. Lunges detected at a depth shallower than $10 \mathrm{~m}$ were excluded from analyses due to possible interference from surface interactions (i.e. abrupt changes in flow noise due to surfacing).

The presence of a lunge was confirmed if the following criteria were met: (1) an isolated bout of fluking (identified from angular accelerations about a lateral axis) associated with a distinct speed maximum, followed by a rapid reduction in speed, followed in turn by a period of gliding; and (2) continued swimming and fluking throughout the lunge, particularly during the deceleration (Goldbogen et al. 2006, 2008, Simon 2010, Ware et al. 2011). The experienced analyst removed any false positive lunges. The times of the confirmed lunges were logged and stored in Excel and plotted with the animal's dive profiles. A feeding dive was defined as any dive for which at least 1 lunge was detected. For each feeding dive, the number of lunges per dive, the dive duration, the post-dive surface time, and the maximum depth were recorded to examine and compare feeding effort and behaviour within and between whales. Least-squares linear regressions were performed to determine the relationships between these parameters. Two-sample Student's $t$-tests were computed to assess the probability that these relationships (e.g. dive duration by number of lunges per dive) were significantly different for the mother and the calf. Two-sample Student's $t$-tests were also used to examine the probability that the pair's mean within-dive inter-lunge intervals were significantly different. A significance level of 0.05 was used for all statistical tests. Synchrony in terms of feeding events was examined by comparing the time and depth of the pair's lunges.

The synchrony of underwater behaviours throughout the concurrent dive records was evaluated using a cross-correlation analysis (Pearson product-moment correlation coefficient for angular and nonangular variables) in the software $\mathrm{R}$ (R Development Core Team 2008). First, to compare the pair's overall similarity in depth, pitch, roll, and heading, we computed correlation coefficients for both the entire concurrent tag records and at lagged time intervals; correlation coefficients (r) vary from 1.0 (highly positively correlated) to -1.0 (highly negatively correlated), with zero corresponding to no correlation. For the purpose of this paper, r-values greater than 0.5 indicated that the animals were generally behaving synchronously (i.e. their behaviours were positively correlated) and r-values greater than 0.9 indicated that the animals were behaving very synchronously (Cohen 1988). When lagging the tracks for the 
cross-correlation analyses, we assumed that if the animals exhibited synchronised behaviours, the cross-correlation function would have the greatest correlation at a lag time close to zero. Second, to examine how synchrony changed over the duration of the concurrent tag records and during different behavioural states (e.g. feeding dives versus nonfeeding dives), we computed r-values for each dive by comparing the depth, pitch, roll, and heading of each of the mother's dives to the calf's respective depth, pitch, roll, and heading at the same times. The percentage of r-values $>0.5$ and $>0.9$ were examined to compare differences in synchronised behaviours between behavioural states (e.g. neither animal feeding during the dive, both animals feeding during the dive, only the mother feeding during the dive, only the calf feeding during the dive). Synchrony of diving and surfacing behaviours was examined by pairing synchronised dives in time and then examining their temporal separation in their descent (when they were submerged $<1 \mathrm{~m}$ depth) and in their surfacing (when they were $>1 \mathrm{~m}$ depth). Synchrony in feeding lunges was also examined by comparing the time and depth of the mother's lunges to the time and depth of the calf's lunges.

\section{RESULTS}

The tags logged 19 h 54 min of concurrent recordings; data reported hereafter refer only to the time when the 2 animals were simultaneously tagged (11:51:17 h May 19, 2010 to 7:46:00 h May 20, 2010). We recorded 285 dives from the mother's tag (maximum depth $=164.04 \mathrm{~m}$, mean $\pm \mathrm{SD}=59.24 \pm 38.19 \mathrm{~m}$ ) and 281 dives from the calf's tag (maximum depth = $249.80 \mathrm{~m}$, mean $\pm \mathrm{SD}=46.20 \pm 39.32 \mathrm{~m}$ ). The pair's vertical proximity was within $20 \mathrm{~m}$ (approximately 2 body lengths) for $71.22 \%$ of the records.

Feeding lunges were identified for both animals (Fig. 2). The mother executed 792 lunges over 246 foraging dives while the calf executed 118 lunges over 30 foraging dives (note: lunges were not included if they were executed shallower than $10 \mathrm{~m}$ ). Prior to feeding, the pair generally rested near the surface (as seen from surface observations during daylight hours) and executed a few exploratory dives (defined here as dives $>50 \mathrm{~m}$ where no lunges were executed). The mother then initiated feeding at 16:22:00 $\mathrm{h}$ and fed continuously and regularly until her tag came off (Fig. 2). The calf, however, initiated feeding at 17:00:08 $\mathrm{h}$ and executed $95.8 \%$ of its lunges by 19:28:21 h. The mother and calf both lunged between one and multiple times per feeding dive (mean \pm SD: $3.22 \pm 1.88$ and $3.93 \pm 2.36$ lunges per dive, respectively), with the maximum number of lunges executed per dive equalling 8 and 9, respectively (Table 1). The mother's within-dive inter-lunge interval was higher and had a smaller variance than the calf's (mean $\pm \mathrm{SD}=46.33 \pm 8.10$ and $33.71 \pm$ $10.32 \mathrm{~s}$, respectively; $t=13.07$, df $=634, \mathrm{p}<0.01$ ); variances between the animals were significantly different $(F=0.62$, df $=546, \mathrm{p}<0.01)$. Additionally, the mother's inter-lunge interval was consistent throughout the tag record $(y=0.02 x+45.92, p<0.01)$ and the change in inter-lunge interval was not significantly different from zero $(\mathrm{p}=0.82)$.

For both animals, an increased number of lunges executed on a foraging dive was associated with longer mean dive durations (mother: $F_{1,252}=5592$, $\mathrm{R}^{2}=0.96, \mathrm{p}<0.01$; calf: $F_{1,28}=33.81, \mathrm{R}^{2}=0.55, \mathrm{p}<$ 0.01), longer mean post-dive surface times (mother: $F_{1,252}=180.90, \mathrm{R}^{2}=0.42, \mathrm{p}<0.01$; calf: $F_{1,28}=32.43$, $\left.\mathrm{R}^{2}=0.54, \mathrm{p}<0.01\right)$, and deeper mean maximum dive depths (mother: $F_{1,252}=735.50, \mathrm{R}^{2}=0.75, \mathrm{p}<0.01$; calf: $\left.F_{1,28}=55.98, \mathrm{R}^{2}=0.67, \mathrm{p}<0.01\right)$. These relationships were more consistent for the mother (always increasing) than for the calf (Table 1, Fig. 3). Additionally, the calf dove shorter and shallower than its mother when comparable numbers of lunges were executed during a given dive (mother versus calf dive duration by number of lunges: $t=-6.79$, df $=$ 282, $\mathrm{p}<0.01$; maximum dive depth by number of lunges: $t=5.45$, df $=282, \mathrm{p}<0.01$ ); However, there was no significant difference in the post-dive surface time between the mother and calf when compared with the number of lunges executed per foraging dive, dive duration, and maximum dive depths (mother versus calf post-dive surface time by number of lunges: $t=-1.71, \mathrm{df}=282, \mathrm{p}=0.09$; post-dive surface time by dive duration: $t=0.63, \mathrm{df}=282, \mathrm{p}=0.53$; and post-dive surface time by maximum dive depth: $t=-0.34$, df $=282$, $\mathrm{p}=0.71$ ).

Cross-correlation analyses of the mother and calf's depth, pitch, roll, and heading for the entire concurrent tracks were derived to determine the correlation of the pair's behaviours. Depth was positively correlated $(r=0.62, \mathrm{p}<0.01)$ and was greatest when the calf's track lagged behind the mother's track by $4.5 \mathrm{~s}$ $(\mathrm{r}=0.62, \mathrm{p}<0.01)$. Pitch and heading were also positively correlated (pitch: $\mathrm{r}=0.35, \mathrm{p}<0.01$; heading: $\mathrm{r}=$ $0.36, \mathrm{p}<0.01$ ); however, this correlation was weaker than the correlation for depth. Pitch and heading were most correlated when the calf's track lagged behind the mother's track by 5 and 11 s, respectively. Rolling was not significantly correlated $(\mathrm{r}=0.02$, 

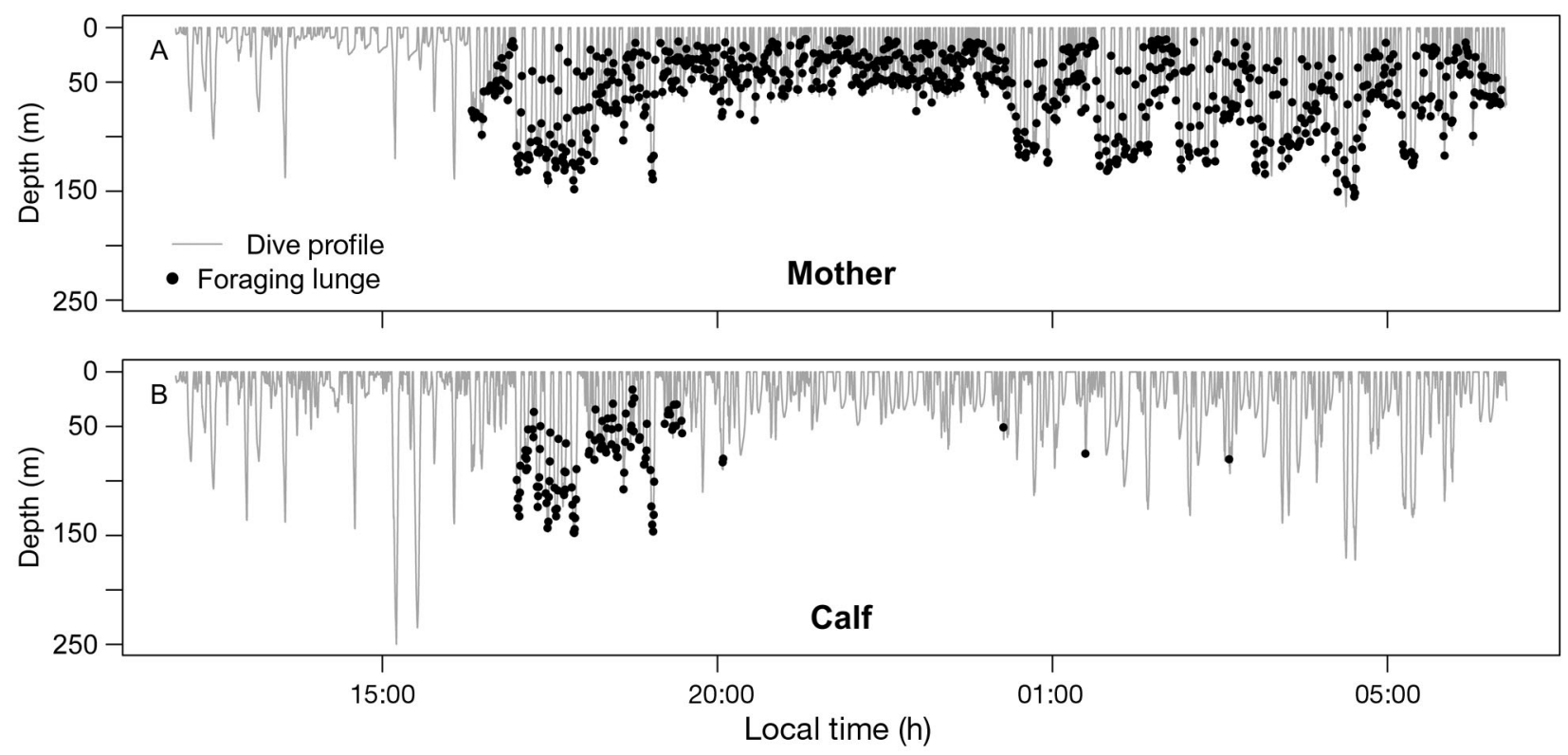

Fig. 2. Megaptera novaeangliae. Dive profiles (depth versus time) and foraging lunges executed by (A) the mother and (B) her calf during the duration of the concurrent tag records. Note: simultaneous recordings began at 11:51:17 h on May 19, 2010, occurred overnight, and ceased when the mother's tag came off at 7:42:00 h on the morning of May 20, 2010

$\mathrm{p}<0.01)$ and was therefore not considered in further analyses. Correlation coefficients calculated for depth, pitch, and heading for each dive varied during the concurrent tag record and will be discussed in more detail below. In terms of their diving and surfacing behaviours, the pair dove and surfaced within $\pm 20 \mathrm{~s}$ of each other for 57.81 and $44.40 \%$ of their dives, respectively. Within these $\pm 20 \mathrm{~s}$ dives, the mother dove and surfaced before the calf $45.27 \%$ and $54.78 \%$ of the time, respectively, while the calf dove and surfaced before the mother 20.95 and $33.91 \%$ of the time, respectively; the pair dove and surfaced at approximately the same time (within \pm 1 s) $33.78 \%$ and $11.30 \%$ of the time, respectively.

Correlation coefficients calculated for the pair's depth, pitch, and heading varied throughout the con- current tag records and between behavioural states (Figs. 4 \& 5). Depth and pitch were highly positively correlated at the beginning of the concurrent record when the animals were resting and gradually weakened when the pair became more active and started making exploratory dives ( 15:30:00 h) (Fig. 4A,B); heading showed a similar pattern but with lower $\mathrm{r}$ values overall (Fig. 4C). Correlation coefficients were highly positively correlated again when the mother initiated feeding (16:22:00 h) and strengthened further when the calf joined its mother in feeding (17:00:08 h). After the calf stopped feeding (19:28:21 $\mathrm{h}$ ), and for the remaining duration of the concurrent records, the correlation coefficients were variable, with lower r-values occurring when the mother was feeding at shallow depths in the middle of the night

Table 1. Megaptera novaeangliae. Mean $( \pm \mathrm{SD})$ values of dive duration, post-dive surface time, and maximum dive depth per number of lunges executed on a dive. (-): not available

\begin{tabular}{|c|c|c|c|c|c|c|c|c|}
\hline \multirow{2}{*}{$\begin{array}{l}\text { Lunges } \\
\text { per dive }\end{array}$} & \multicolumn{2}{|c|}{ No. of dives } & \multicolumn{2}{|c|}{ Dive duration (s) } & \multicolumn{2}{|c|}{ Post-dive surface time (s) } & \multicolumn{2}{|c|}{ Max. dive depth (m) } \\
\hline & Mother & Calf & Mother & Calf & Mother & Calf & Mother & Calf \\
\hline 1 & 69 & 5 & $36.20 \pm 9.53$ & $172.64 \pm 74.91$ & $21.22 \pm 18.83$ & $30.72 \pm 30.29$ & $22.21 \pm 6.11$ & $64.33 \pm 21.21$ \\
\hline 2 & 23 & 6 & $94.68 \pm 15.40$ & $156.93 \pm 86.95$ & $25.60 \pm 18.58$ & $54.13 \pm 43.04$ & $45.38 \pm 14.18$ & $60.87 \pm 16.05$ \\
\hline 3 & 48 & 4 & $151.78 \pm 20.52$ & $149.80 \pm 21.54$ & $34.67 \pm 27.27$ & $45.20 \pm 28.43$ & $66.06 \pm 16.35$ & $71.67 \pm 11.20$ \\
\hline 4 & 47 & 3 & $209.61 \pm 27.28$ & $186.93 \pm 31.19$ & $62.55 \pm 33.69$ & $45.87 \pm 32.62$ & $75.80 \pm 25.52$ & $84.24 \pm 20.72$ \\
\hline 5 & 27 & 4 & $260.03 \pm 36.39$ & $220.40 \pm 47.90$ & $67.97 \pm 42.07$ & $81.40 \pm 52.19$ & $87.24 \pm 26.40$ & $78.20 \pm 8.13$ \\
\hline 6 & 16 & 2 & $309.39 \pm 23.93$ & $310.40 \pm 2.26$ & $97.92 \pm 54.19$ & $97.20 \pm 14.14$ & $113.53 \pm 25.07$ & $140.02 \pm 10.25$ \\
\hline 7 & 13 & 4 & $354.07 \pm 21.01$ & $294.60 \pm 25.21$ & $89.27 \pm 41.90$ & $147.80 \pm 45.73$ & $125.99 \pm 21.00$ & $118.36 \pm 19.08$ \\
\hline 8 & 3 & 1 & $387.60 \pm 32.02$ & 346.4 & $140.40 \pm 16.74$ & 129.6 & $138.19 \pm 11.25$ & 146.79 \\
\hline 9 & 0 & 1 & - & 382.4 & - & 172.0 & - & 150.36 \\
\hline
\end{tabular}


Mother
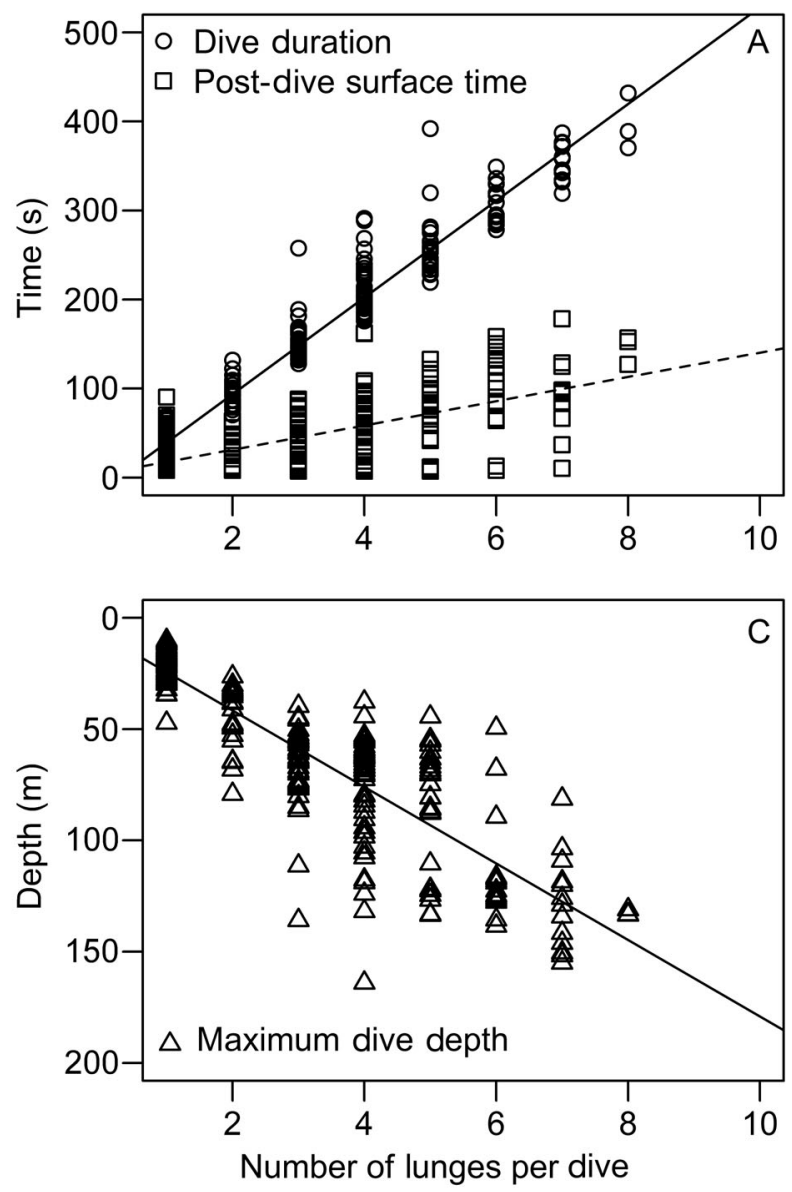

\section{Calf}
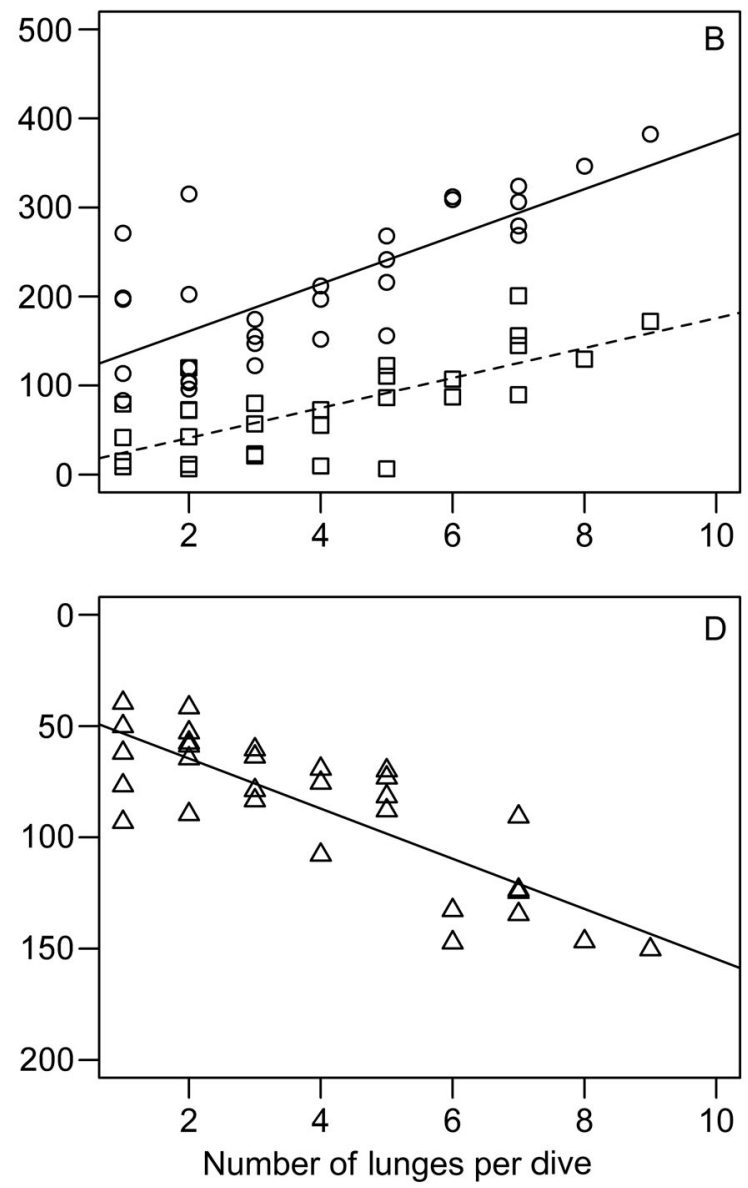

Fig. 3. Megaptera novaeangliae. Mean $(\mathrm{A}, \mathrm{B})$ dive duration $(\mathrm{s})$ and post-dive surface time $(\mathrm{s})$, and $(\mathrm{C}, \mathrm{D}) \mathrm{maximum}$ depth $(\mathrm{m})$ (and associated best fit lines from least-squared linear regressions) for foraging dives of the mother and her calf

(presumably following the diel vertical migration of krill) and higher r-values when the mother was performing deeper foraging dives later in the morning. The percentage of r-values for depth, pitch, and heading that were $>0.5$ and $>0.9$ for the varying behavioural states (Fig. 5) are shown in Table 2 (note: there were no dives during which only the calf was foraging).

Lunges performed by the calf appeared to be synchronised with lunges performed by its mother in terms of time and depth. Indeed, 84.26 and $79.63 \%$ of the calf's lunges were performed within $\pm 20 \mathrm{~s}$ and within $\pm 20 \mathrm{~m}$, respectively, of its mother's lunges, while 35.19 and $53.70 \%$ were performed within $\pm 5 \mathrm{~s}$ and within $\pm 5 \mathrm{~m}$, respectively. Of these, the mother lunged before the calf $60.19 \%$ of the time and shallower than the calf $52.78 \%$ of the time. In addition, $97.46 \%$ of the calf's lunges were executed during a dive in which its mother was also foraging. The mother, however, did not appear to forage based on whether or not her calf was simultaneously foraging or exhibiting synchronised behaviours (based on the continuity and regularity of her within-dive interlunge intervals).

\section{DISCUSSION}

Here, we describe the first record of a long-term $(\sim 20 \mathrm{~h})$ continuous underwater relationship and concurrent foraging behaviour of a baleen whale mother-calf pair. As the calf we tagged was likely between 8 and 12 mo old (assuming it was born in the previous winter or early spring), our findings represent a snapshot of the period of time when the calf was gaining independence and was becoming more responsible for maintaining proximity to its mother. This is supported by the mother's foraging behaviour, which did not appear to change according to changes in the calf's behaviour (e.g. her inter-lunge interval was consistent and stable for the duration of the time she spent foraging, despite changes in the calf's 


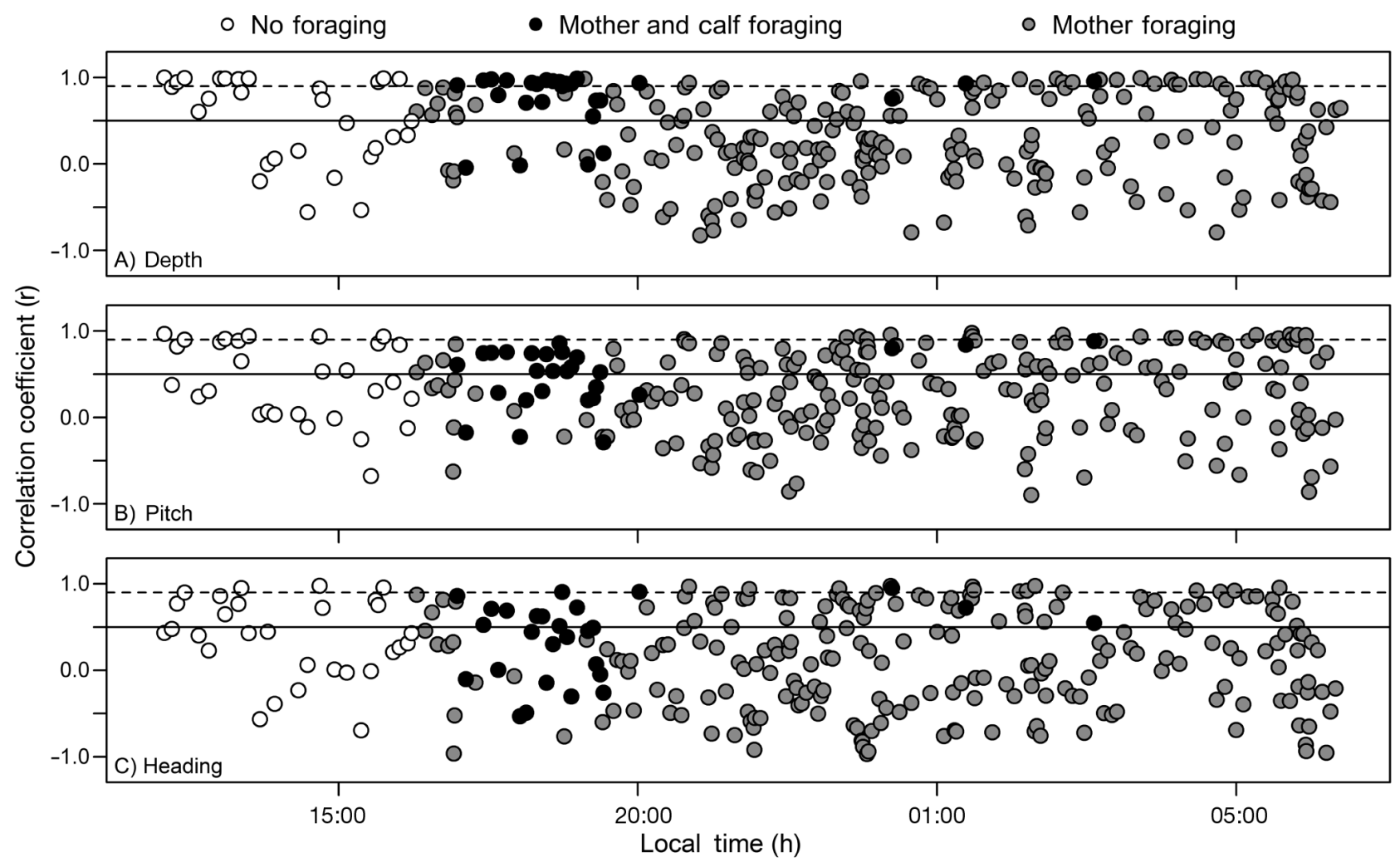

Fig. 4. Megaptera novaeangliae. Pearson's product-moment correlation coefficients calculated for each dive for the duration of the concurrent tag records for (A) depth, (B) pitch and (C) heading behaviour. The solid horizontal line represents $\mathrm{r}=0.5$

(i.e. synchronised behaviour), while the dashed horizontal line represents $r=0.9$ (i.e. highly synchronised behaviour)

behaviour), and was instead likely a function of the vertical position of the prey (Croll et al. 2005, Friedlaender et al. 2009, Hazen et al. 2009, Goldbogen et al. 2011). In accordance, the calf appeared to be primarily responsible for altering and synchronising its behaviours to its mother throughout the concurrent tag records. This is similar to other humpback whale calves (Szabo \& Duffus 2008, Cartwright \& Sullivan 2009), southern right whale calves (Taber \& Thomas 1982, Thomas \& Taber 1984), and other mammals, such as infant rhesus monkeys Macaca mulatta (Berman 1980), during the later stages of the motheroffspring relationship.

While both animals exhibited feeding lunges, there were some striking differences in the frequency and duration of their foraging behaviours that likely correspond to the changes associated with the calf gaining nutritional independence and weaning. For instance, as previously stated, once the mother began feeding, she continued to consistently and regularly feed without resting for any significant period of time. In addition, she executed more lunges $(\mathrm{N}=792)$ than have previously been described for other adult humpback whales (unknown age and/or sex) tagged for similar durations in the WAP (Ware et al. 2011). These findings may be explained by her spending less energy on her calf due to the calf's decreasing vulnerability to being left alone more frequently and for longer periods of time, and spending more energy attending to the increased demands on her personal fitness (e.g. replenishing energy reserves diminished from lactation and the recent migration, and increasing energy reserves for successful future migrations and successful rearing of additional offspring).

While the calf may have still been nursing (although we saw no apparent evidence of its occurrence), it executed 118 feeding lunges over 30 dives. Interestingly, the calf primarily foraged between 17:00:08 and 19:28.21 h. There are several potential reasons for why its foraging behaviour was so discrete in frequency and in duration. First, if the calf was still nursing then its feeding lunges were likely to obtain supplemental energy in addition to nursing. Second, the calf may require proportionally less food than larger animals to support its resting metabolism. Third, when young animals are less active their metabolic rates decline (Arnould et al. 2003) and energy is preferentially allocated to growth (Sibley \& Calow 


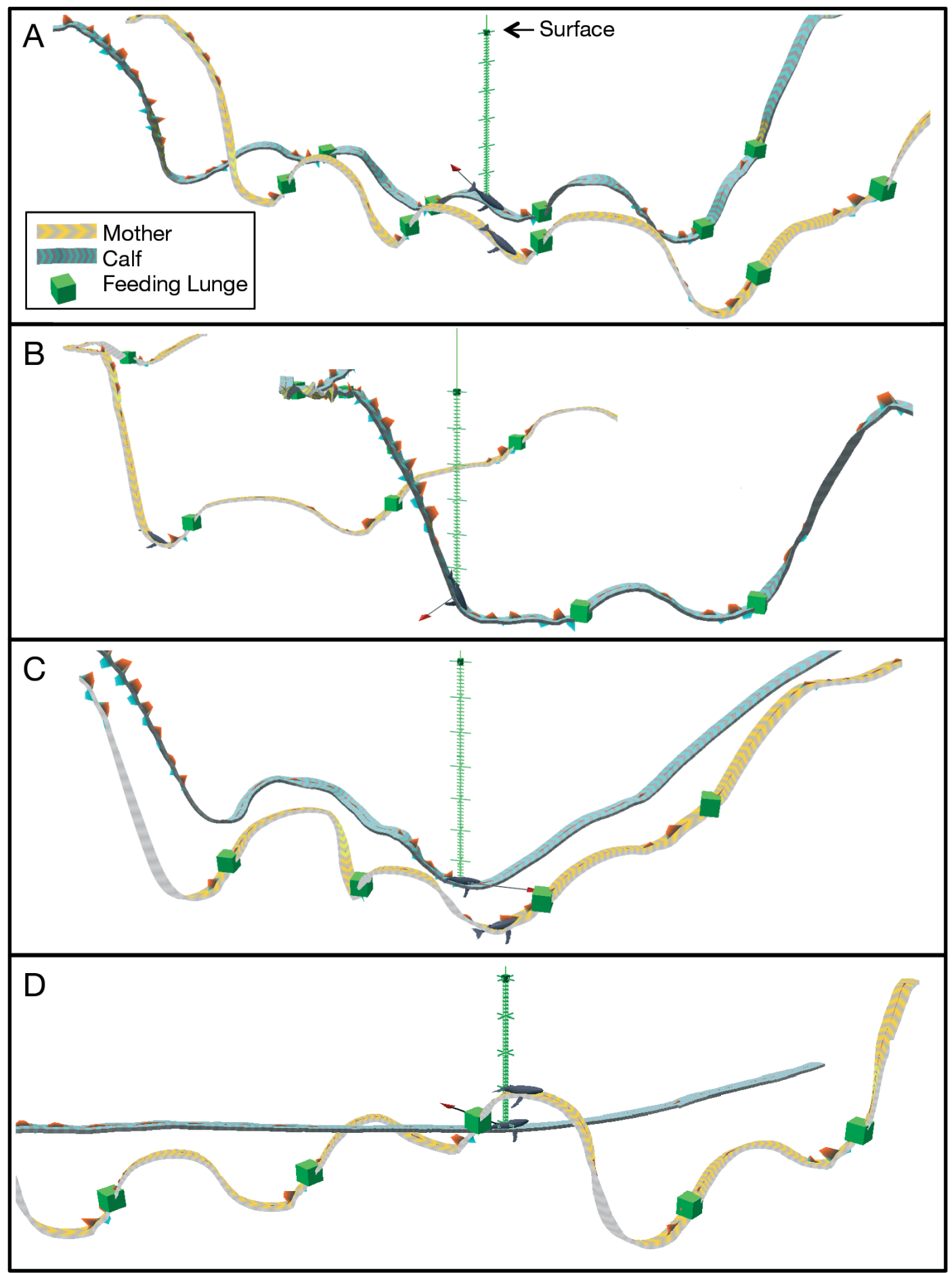

Fig. 5. Megaptera novaeangliae. Three-dimensional visualisations of the mother and calf's dive behaviour during varying behavioural states (TrackPlot, Ware et al. 2006). The dashed vertical line represents depth (10 m increments from the surface), the horizontal arrow represents magnetic north, and the blue and red wedges along the track represent the magnitude and frequency of fluke strokes (identified from angular accelerations about a lateral axis). Note: horizontal proximity is approximated based on surface fixes ( $\mathrm{N}=30$ and 27 for the mother and calf, respectively) and dead-reckoning techniques, and may not represent the true horizontal proximity. (A) A synchronised dive during which both animals are foraging; (B) an unsynchronised dive during which both animals are foraging; $(\mathrm{C})$ a synchronised dive during which the mother is foraging and the calf is not foraging but swimming nearby; and (D) an unsynchronised dive during which the mother is foraging and the calf is not foraging and not swimming synchronously 
Table 2. Megaptera novaeangliae. Percentage of correlation coefficients that were greater than 0.5 (synchronous behaviour; 1st value) and greater than 0.9 (highly synchronous behaviour; 2nd value) for the pair's depth, pitch, and heading

\begin{tabular}{|lccc|}
\hline & Depth & Pitch & Heading \\
\hline Neither foraging & $62.07,34.48$ & $48.28,17.24$ & $37.93,10.34$ \\
Both foraging & $85.19,59.26$ & $62.96,0.00$ & $48.15,11.11$ \\
$\begin{array}{l}\text { Only mother } \\
\text { foraging }\end{array}$ & $36.36,10.45$ & $38.18,9.09$ & $31.36,6.36$ \\
\hline
\end{tabular}

1986). Thus, it may be beneficial for the calf to spend only a small portion of its time feeding and a larger portion of its time either resting near the surface or swimming in synchrony with its mother gaining the associated hydrodynamic advantage (Noren et al. 2008, Noren \& Edwards 2011). This would allow the calf to dedicate more of its energy to growth, which is important for its survival; a large body size reduces the costs associated with travel during migrations (Williams 1999), increases the individual's breath holding and oxygen storage capacity (Schreer \& Kovacs 1997), reduces the risk of predation (Chittleborough 1958), and enhances future reproductive success (Spitz et al. 2002).

While adult rorqual dives have been characterised by a gliding descent with a low rate of fluking, a series of lunges at depth, and an ascent to the surface powered by steady fluking (Goldbogen et al. 2006, 2008), preliminary examinations of the calf's dive plot reveal that the calf beats its flukes frequently on the descent, performs a series of lunges at depth, and then ascends to the surface with few, if any, fluke strokes. Positively buoyant whales, such as North Atlantic right whales Eubalaena glacialis (Nowacek et al. 2001) and sperm whales Physeter macrocephalus (Miller et al. 2004) are known to actively stroke to depth and glide during ascent. Aoki et al. (2011) found that an increase in fat content in a Northern elephant seal Mirounga angustirostris resulted in an increased descent stroke rate and decreased ascent stroke rate. This suggests that the calf is more buoyant than its mother and must expend more energy to stay submerged. Further work to characterise buoyancy and fluking effort differences between mother and calf pairs should be conducted to examine this hypothesis more closely.

The frequency of lunges executed per dive has been associated with deeper maximum dive depths, longer dive durations, and longer post-dive surface times in humpback whales (Dolphin 1987a,b, Goldbogen et al. 2008, Ware et al. 2011), fin whales (Croll et al. 2001, Acevedo-Gutiérrez et al. 2002, Goldbo- gen et al. 2006, 2007), and blue whales (Croll et al. 2001, Acevedo-Gutiérrez et al. 2002, Goldbogen et al. 2011). Our results (Fig. 3, Table 1) are consistent with these findings and thus provide further support for the hypothesis that lunge feeding is energetically costly. Interestingly, the mother and calf had proportionally equivalent post-dive surface times (i.e. recovery times) when considering the number of lunges executed per dive, dive durations, and maximum dive depths. This suggests that foraging dives executed by the mother and calf of comparable foraging effort were equivalently energetically costly. Despite this, the calf dove shallower and had shorter dive durations than its mother for comparable number of lunges executed per dive. These findings are likely related to the calf's limited oxygen capacity and possibly greater buoyancy. The duration for which a diving animal can remain underwater is related to its oxygen storage capacity, the rate at which it uses stored oxygen, and its anaerobic capacity (Schreer \& Kovacs 1997); as such, larger animals are better equipped to dive. Thus, a humpback calf should exhibit shorter dives for similar dive depths and durations than its larger mother.

Our results also further support the hypothesis that humpback whales exhibit a following maternal strategy (Lent 1974, Szabo \& Duffus 2008). While our pair was not always traveling together, they were within a vertical distance of $\pm 20 \mathrm{~m}$ for $71.40 \%$ of the concurrent records and exhibited a high percentage of synchronised dives in terms of their depth, pitch, and heading (Fig. 4, Table 2). In addition, the pair's depth was most highly correlated when the calf's track was lagged $4.5 \mathrm{~s}$ behind its mother. Also, when the calf was feeding, it lunged after its mother $60.2 \%$ of the time. These findings suggest that the pair were generally traveling and feeding in synchrony with each other, with the calf traveling and feeding close behind.

Interestingly, a higher percentage of positively correlated dives were found when both animals were feeding than when neither animal was feeding or when just the mother was feeding. There are several beneficial reasons for the calf to synchronise its feeding behaviour with its mother, including learning how to forage and/or benefiting from the food its mother has found. In addition, synchrony during foraging may ease the energetic costs associated with foraging for the calf by gaining the hydrodynamic advantages associated with synchronised swimming (Noren et al. 2008, Noren \& Edwards 2011). This may contribute to the equivalent recovery times we found for the mother and the calf for comparable foraging 
dive efforts. When the calf was not feeding, it would go in and out of synchrony with its mother (shown by the fluctuation in r-values; Fig. 4), generally behaving independently of its mother when its mother was feeding near the surface and re-synchronising its behaviours when the mother made deeper feeding dives. This suggests that while the mother was feeding near the surface, the calf could behave independently of its mother while maintaining a close proximity. However, when the mother executed deeper dives, the calf had to join and synchronise its behaviour in order to maintain similar levels of proximity.

While our findings only represent $\sim 20 \mathrm{~h}$ of a single humpback whale mother-calf pair, they demonstrate how bio-logging tools can enhance our understanding of marine animals during periods that are critical for their behavioural development. It is important to note that the behaviour of mother-calf pairs can vary widely across pairs and over time (Taber \& Thomas 1982, Cartwright \& Sullivan 2009) and therefore more tags need to be deployed on additional mother-calf pairs at varying times during the first year of their relationship. Such attempts should take the appropriate measures to minimise disturbance during tagging, however, as mother-calf pairs may be more sensitive to boat approaches than groups of adults. These efforts will enable us to gain a better understanding of early baleen whale behavioural ontogeny.

Acknowledgements. We thank J. Hench, P. Halpin, J. Goldbogen, M. Johnson, D. Cyr, D. Rubenstein, and the RVIB 'Nathaniel B. Palmer' officers, crew and marine technicians for their invaluable assistance. We also thank M. DunphyDaly and 3 anonymous reviewers for their valuable comments on an earlier draft of this paper. This research was conducted under NMFS MMPA Permit 808-1735 and Antarctic Conservation Act Permit 2009-014, and was supported by NSF grant number ANT-07-39483. TrackPlot was developed under the Tools to Compare Diving-Animal Kinematics with Acoustic Behaviour and Exposure grant number N0014091601.

\section{LITERATURE CITED}

Acevedo-Gutiérrez A, Croll DA, Tershy BR (2002) High feeding costs limit dive time in the largest whales. J Exp Biol 205:1747-1753

- Aoki K, Watanabe YY, Crocker DE, Robinson PW, and others (2011) Northern elephant seals adjust gliding and stroking patterns with changes in buoyancy: validation of at-sea metrics of body density. J Exp Biol 214:2973-2987

> Arnould JPY, Luque SP, Guinet C, Costa DP, Kingston J, Shaffer SA (2003) The comparative energetics and growth strategies of sympatric Antarctic and subantarctic fur seal pups at Iles Crozet. J Exp Biol 206:4497-4506

Baker CS, Herman LM, Perry A, Lawton WS, and others (1986) Migratory movement and population structure of humpback whales (Megaptera novaeangliae) in the central and eastern North Pacific. Mar Ecol Prog Ser 31: 105-119

> Baraff L, Weinrich MT (1993) Separation of humpback whale mothers and calves on a feeding ground in early autumn. Mar Mamm Sci 9:431-434

Bel'Kovich VM (1991) Herd structure, hunting, and play: bottlenose dolphins in the Black Sea. In: Pryor K, Norris K (eds) Dolphin societies: discoveries and puzzles. University of California Press, Berkeley, CA, p 17-78

Bender CE, Herzing DL, Bjorklund DF (2009) Evidence of teaching in atlantic spotted dolphins (Stenella frontalis) by mother dolphins foraging in the presence of their calves. Anim Cogn 12:43-53

Berman CM (1980) Mother-infant relationships among freeranging rhesus monkeys on Cayo Santigo: a comparison with captive pairs. Anim Behav 28:860-873

Brodie PF (1993) Noise generated by the jaw actions of feeding fin whales. Can J Zool 71:2546-2550

Cartwright R, Sullivan M (2009) Behavioral ontogeny in humpback whale (Megaptera novaeangliae) calves during their residence in Hawaiian waters. Mar Mamm Sci 25:659-680

Chittleborough RG (1958) The breeding cycle of the female humpback whale, Megaptera nodosa (Bonaterre). Aust J Mar Freshwater Res 9:1-8

> Chittleborough RG (1965) Dynamics of two populations of the humpback whale, Megaptera novaeangliae (Borowski). Aust J Mar Freshwater Res 16:33-128

Clapham PJ (1996) The social and reproductive biology of humpback whales: an ecological perspective. Mammal Rev 26:27-49

> Clapham PJ, Mayo CA (1987) Reproduction and recruitment of individually identified humpback whales, Megaptera novaeangliae, observed in Massachusetts Bay, 1979-1985. Can J Zool 65:2853-2863

Cohen J (1988) Statistical power analysis for the behavioral sciences, 2nd edn. Lawrence Erlbaum Associates, Hillsdale, NJ

> Croll DA, Acevedo-Gutiérrez A, Tershy BR, Urban-Ramirez $\mathrm{J}$ (2001) The diving behavior of blue and fin whales: is dive duration shorter than expected based on oxygen stores? Comp Biochem Physiol A Mol Integr Physiol 129: 797-809

Croll DA, Marinovic B, Benson S, Chavez FP, Black N, Ternullo R, Tershy BR (2005) From wind to whales: trophic links in a coastal upwelling system. Mar Ecol Prog Ser 289:117-130

> Dolphin WF (1987a) Dive behavior and estimated energy expenditure of foraging humpback whales in southeast Alaska. Can J Zool 65:354-362

> Dolphin WF (1987b) Ventilation and dive patterns of humpback whales, Megaptera novaeangliae, on their Alaskan feeding grounds. Can J Zool 65:83-90

> Espmark Y (1971) Mother-young relationship and ontogeny of behaviour in reindeer (Rangifer tarandus L.). Z Tierpsychol 29:42-81

Estes RD (1976) The significance of breeding synchrony in wildebeest. East Afr Wildl J 14:135-152

Fellner W, Bauer GB, Harley HE (2006) Cognitive implications of synchrony in dolphins: a review. Aquat Mamm 32:511-516

> Fisher DO, Blomberg SP, Owens IPF (2002) Convergent maternal care strategies in ungulates and macropods. Evolution 56:167-176 
Florez-Gonzalez L (1991) Humpback whales Megaptera novaeangliae in the Gorgona Island, Colombia Pacific breeding waters: population and pod characteristics. Mem Queensl Mus 20:291-295

Friedlaender AS, Hazen EL, Nowacek DP, Halpin PN, and others (2009) Diel changes in humpback whale Megaptera novaeangliae feeding behavior in response to sand lance Ammodytes spp. behavior and distribution. Mar Ecol Prog Ser 395:91-100

- Goldbogen JA, Calambokidis J, Shadwick RE, Oleson EM, McDonald MA, Hildebrand JA (2006) Kinematics of foraging dives and lunge-feeding in fin whales. J Exp Biol 209:1231-1244

Goldbogen JA, Pyenson ND, Shadwick RE (2007) Big gulps require high drag for fin whale lunge feeding. Mar Ecol Prog Ser 349:289-301

Goldbogen JA, Calambokidis J, Croll DA, Harvey JT, and others (2008) Foraging behavior of humpback whales: kinematic and respiratory patterns suggest a high cost for a lunge. J Exp Biol 211:3712-3719

Goldbogen JA, Calambokidis J, Oleson E, Potvin J, Pyenson ND, Schorr G, Shadwick RE (2011) Mechanics, hydrodynamics and energetics of blue whale lunge feeding: efficiency dependence on krill density. J Exp Biol 214: 131-146

Gubbins C, McCowan B, Lynn SK, Hooper S, Reiss D (1999) Mother-infant spatial relations in captive bottlenose dolphins, Tursiops truncatus. Mar Mamm Sci 15:751-765

Hazen EL, Friedlaender AS, Thompson MA, Ware CR, Weinrich MT, Halpin PN, Wiley DN (2009) Fine-scale prey aggregations and foraging ecology of humpback whales Megaptera novaeangliae. Mar Ecol Prog Ser 395: 75-89

Johnson MP, Tyack PL (2003) A digital acoustic recording tag for measuring the response of wild marine mammals to sound. IEEE J Oceanic Eng 28:3-12

Lent PC (1974) Mother-infant relationships in ungulates. In: Geist V, Walther F (eds) The behaviour of ungulates and its relation to management, Vol 24. IUCN, Morges, p 14-55

- Lockyer C (2007) All creatures great and smaller: a study in cetacean life history energetics. J Mar Biol Assoc UK 87: 1035-1045

Mackintosh NA (1965) The stocks of whales. Fishing News (Books), London

> Miller PJO, Johnson MP, Tyack PL, Terray EA (2004) Swimming gaits, passive drag and buoyancy of diving sperm whales Physeter macrocephalus. J Exp Biol 207: 1953-1967

Noren SR, Edwards EF (2011) Infant position in mother-calf dolphin pairs: formation locomotion with hydrodynamic benefits. Mar Ecol Prog Ser 424:229-236

Noren SR, Biedenbach G, Redfern JV, Edwards EF (2008) Hitching a ride: the formation locomotion strategy of dolphin calves. Funct Ecol 22:278-283

> Norris KS, Schilt CR (1988) Cooperative societies in threedimensional space: on the origin of aggregations, flocks, and schools, with special reference to dolphins and fish. Ethol Sociobiol 9:149-179

- Nowacek DP, Johnson MP, Tyack PL, Shorter KA, McLellan WA, Pabst DA (2001) Buoyant balaenids: the ups and downs of buoyancy in right whales. Proc R Soc Lond B 268:1811-1816

Nowacek DP, Johnson MP, Tyack PL (2004) North Atlantic right whales (Eubalaena glacialis) ignore ships but respond to alerting stimuli. Proc R Soc Lond B 271:227-231

Pivorunas A (1979) Feeding mechanisms of baleen whales. Am Sci 67:432-440

Potvin J, Goldbogen JA, Shadwick RE (2009) Passive versus active engulfment: verdict from trajectory simulations of lunge-feeding fin whales Balaenoptera physalus. J R Soc Interface 6:1005-1025

R Development Core Team (2008) R: a language and environment for statistical computing. R Foundation for Statistical Computing, Vienna

Sargeant BL, Mann J (2009) Developmental evidence for foraging traditions in wild bottlenose dolphins. Anim Behav 78:715-721

Schreer JF, Kovacs KM (1997) Allometry of diving capacity in air-breathing vertebrates. Can J Zool 75:339-358

Sibley RM, Calow P (1986) Physiological ecology of animals: an evolutionary approach. Blackwell Scientific Publications, Oxford

Simon M (2010) The sounds of whales and their food: baleen whales, their foraging behaviour, ecology and habitat use in an arctic habitat. $\mathrm{PhD}$ dissertation, Aarhus University

Spitz SS, Herman LM, Pack AA, Deakos MH (2002) The relation of body size of male humpback whales to their social roles on the Hawaiian winter grounds. Can J Zool 80:1938-1947

Szabo A, Duffus D (2008) Mother-offspring association in the humpback whale, Megaptera novaeangliae: following behaviour in an aquatic mammal. Anim Behav 75: 1085-1092

Taber S, Thomas P (1982) Calf development and mother-calf spatial relationships in southern right whales. Anim Behav 30:1072-1083

Thomas PO, Taber SM (1984) Mother-infant interaction and behavioral development in southern right whales, Eubalaena australis. Behaviour 88:42-60

Van Lennep EW, Van Utretcht WL (1953) Preliminary report on the study of the mammary glands of whales. Norsk Hvalangst-Tidende 42:249-258

- Ware C, Arsenault R, Plumlee M (2006) Visualizing the underwater behavior of humpback whales. IEEE Comput Graph Appl 26:14-18

> Ware C, Friedlaender AS, Nowacek DP (2011) Shallow and deep lunge feeding of humpback whales in fjords of the West Antarctic Peninsula. Mar Mamm Sci 27:587-605

Weihs D (2004) The hydrodynamics of dolphin drafting. J Biol 3:8

> Whiten A (2001) Imitation and cultural transmission in apes and cetaceans. Behav Brain Sci 24:359-360

> Whiten A, Ham R (1992) On the nature and evolution of imitation in the animal kingdom: reappraisal of a century of research. Adv Stud Behav 21:239-283

Williams TM (1999) The evolution of cost efficient swimming in marine mammals: limits to energetic optimization. Phil Trans R Soc Lond B 354:193-201

- Würsig B, Dorsey EM, Fraker MA, Payne RS, Richardson WJ, Wells RS (1984) Behavior of bowhead whales, Balaena mysticetus, summering in the Beaufort Sea: surfacing, respiration, and dive characteristics. Can J Zool 62: 1910-1921

- Zoidis AM, Smultea MA, Frankel AS, Hopkins JL, and others (2008) Vocalizations produced by humpback whale (Megaptera novaeangliae) calves recorded in Hawaii. J Acoust Soc Am 123:1737-1746 